\title{
Effect of Teaching Program On Nurses' Performance About Hematuria at Urology Intensive Care Unit.
}

\author{
Hager A. Hussein ${ }^{1}$, Mohammed A. Elgammal' ${ }^{2}$ Mona A. Mohammed ${ }^{3}$ \&Aml I. Abdel hafiz ${ }^{4}$. \\ 1. Specialist nursing at urology hospital, Assuit University, Egypt. \\ 2. Professor of urology medicine, faculty of medicine, Assuit University, Egypt. \\ 3. Assistant professor of critical care and emergency nursing, faculty of nursing, Assuit University, Egypt. \\ 4. Lecture of critical care and emergency nursing, faculty of nursing, Assuit University, Egypt.
}

\begin{abstract}
Hematuria is a life threating problem which lead to anemia and hypovolemic shock due to bleeding which affect patient life; so nurses must do great efforts to prevent complications by using urine color scale successfully to contribute a successful patients' outcomes. Aim: Evaluate the effect of teaching program about hematuria on nurses' performance at urology intensive care unit. Research design: This study was a quasi experimental design, conducted in urological intensive care unit and urological emergency unit at Assuit university hospital. Subject and method: This study was composed of 50 nurses caring patients with hematuria. Twotools were used for data collection, tool I is (knowledge assessment tool), tool II is (observational checklist). Results: The study revealed that more than half of nurses were in the age group from 20 to 25 years and held nursing technician institute, $92.0 \%$ of nurses had unsatisfactory knowledge about hematuria , but this knowledge improved after the implementation of the program. Conclusion and Recommendations: Nurses' had unsatisfactory knowledge about hematuria in pretest. The educational program was successful in achieving its goal of upgrading or improving nurse`s knowledge. A significant difference was found between scores of knowledge before and after implementing the program. The study recommends focused on establishing plans for periodical and scheduled training courses and educational programs for nurses to help in improving their knowledge.
\end{abstract}

\section{Keywords: Teaching Program, Intensive Care Unit, Performance, Hematuria \& Urine color scale.}

\section{Introduction}

Haematuria is defined by the presence of more than two red blood cells (RBCs) per high-power field in the urine on at least two to three different occasions, independent of trauma, exercise, menstruation or sexual activity, (Moreno et al., 2016).

Hematuria has a pathogenic role in promoting kidney disease progression. An increased risk for end-stage renal disease has been reported in adolescents and young adults with, any part of the kidneys or urinary tract (ureters, urinary bladder, prostate, and urethra) can leak blood into the urine, (Koo et al., 2016). Urethral obstruction and anemia remains the major potential complications due to gross hematuria; so this program help nurses to decrease the incidence of hypovolemic shock, (Yuste et al., 2015).

Nurses must immediately assess severity of bleeding and facilitate patency of urinary outflow. Monitoring for hemodynamic instability with intravenous fluid infusion or red blood cell transfusions as indicated may be necessary; however, for many patients with advanced disease, such interventions may be inappropriate given clarified goals of care, or simply cannot be administered in a given care setting (e.g. home, long term care, inpatient hospice), (Groninger et al., 2012).
Urine color scale (UCS) is a simple, effective, objective and visual tool with 3 colors depicting hydration status and 4 depicting macroscopic hematuria, together with instructions for use on the reverse side. UCS used to communicate urine color for health professionals, provide consistency in reporting urine appearance and improve accuracy of treatment whether indwelling catheter (IDC) can be removed, continuous irrigation may cease, patient is actively bleeding or has old blood, patient well hydrated or dehydrated determined by communication about urine appearance and take actions about IV/oral fluid intake, IDC removal, bladder irrigation, (Meagher et al., 2014).

Planned health education program can be used effectively to improve the knowledge and practice regarding hematuria care among the nursing staff. It must to keep reinforcing the performance regarding this. Such structured education will improve the knowledge and practice of staff nurses. Suitable intervention packages need to be developed and in service education need to be given periodically for the effectiveness of qualitative nursing services, (Madiha, et al., 2017). 


\section{Significance of the study}

Hematuria is a sign of a large number of diseases of the kidneys and the urinary tract, ranging from trivial to lethal and is usually alarming to patients. $30 \%$ of patients presenting with painless hematuria are found to have a malignancy, it's a commonly seen condition in the emergency department. Nurses should have knowledge, good practice and be skillful in dealing with this hematuria, so there is a need for a study to promote the nurses' knowledge that could help them to contribute a successful patients' care, (Grossfeld GD et al, 2001).

\section{Aim of the study}

Evaluate the effect of teaching program about hematuria on nurses' performance at urology intensive care unit.

\section{Research Hypotheses}

1. Improved knowledge and practice score obtained by nurses who had received teaching program.

2. Improved nurses' performance after introducing the program.

\section{Subject \& Methods \\ Research design:}

A quasi experimental research design (pre-posttest), Thus only one group is observed twice (before and after introducing the program).

\section{Setting}

The study was conducted in urological intensive care unit and urological emergency department at Assuit university hospital.

\section{Sample:}

Convenient sample of all nurses working in selected setting (about 50 nurses) included in the study.

\section{Study tools}

Two tools were used in this study: TOOL I :( knowledge assessment questionnaire) This tool consisted of structured multiple choice (pre/posttest questionnaire tool). This tool was developed by researcher after reviewing literature (Urden et al., 2016), to assess the knowledge level of critical care nurses regarding patients with hematuria. This tool included two part: Part 1: Demographic data of study sample which include sex close ended questions (age, sex, educational level, marital status, years of experience and previous training program).

Part 2: This part included twenty questions to assess nurse`s basic knowledge about hematuria, nursing management, urine analysis and urine color scale, (India PvT, 2014, Hicks D \& Li CH, 2007).

Scoring system for nurses' knowledge: All items had three alternative answers. A score value of one was awarded to each correct answer and zero was allotted for wrong answer (satisfactory $>75$ and unsatisfactory $<75 \%$ based on statistical analysis).

TOOL II: Pre/post nurse's practice: This tool covered all the steps procedure of nursing care for patients with hematuria:

Part 1: Observational checklist includes performing catheter care procedure, collecting urine specimen procedure, obtaining a urine specimen from urinary catheter, performing intermittent closed catheter irrigation, administering continuous closed catheter irrigation and removing an indwelling catheter, (Lynn P, 2015).

Part 2: Developing and testing a urine color reference scale for hematuria, with 3 colors depicting hydration status and 4 depicting macroscopic hematuria, together with instructions for use on the reverse side. Whether indwelling catheter (IDC) can be removed, continuous irrigation may cease, patient is actively bleeding or has old blood, patient well hydrated or dehydrated determined by communication about urine appearance and take actions about IV/oral fluid intake,(Meagher, \& et al., 2014).

Scoring system for nurses' skills: Total score for all steps were 76 and every step was evaluated as follows; correctly done was scored 1, incorrectly done and not done was scored 0 (satisfactory $>75$ and unsatisfactory $<75 \%$ based on statistical analysis).

\section{Ethical consideration}

The study will follow common ethical principles in clinical research and research proposal will be approved from ethical committee in the faculty of nursing.

\section{Construction of the teaching program}

The teaching program was developed by the researcher based on the previous assessment of nurses` knowledge and skills, available resources and review of relevant literature.

The study was conducted on three phases (preparatory phase, implementation phase and evaluation phase).

\section{preparatory phase}

- Permission to conduct the study was obtained from the hospital responsible authorities after explanation of the aim of the study; Permission for voluntary participation was obtained from nurses after explaining the nature and purpose of the study.

- Tool one used in this study was developed in Arabic by the researcher based on reviewing the relevant literatures.

- The tools were tested for content related validity by jury of five specialists in the field of critical care nursing and specialists in urology medicine.

- A pilot study was conducted on five nurses to test the feasibility and applicability of the tools and the necessary modification was done. 
Implementation and evaluation phase

- All nurses were interviewed during break time (two hours) in different shifts or before beginning of shift, the total sample will be divide into subgroups include 5 nurses each session for better performance and understanding.

\section{Assessment of knowledge was done twice as follows}

- Once at beginning of study was considered as pretest assessment and as base line data for latter comparison with future posttest.

- The second administration of questionnaire was carried out after implementation of the teaching program to identify its effect on nurses' knowledge.

Assess nurses' skills:

- The researcher observes the nurses' skills using observational checklist tool after program implementation.

- The researcher completes the checklist while the nurses demonstrate program.

\section{Implementation of the program}

- The researcher introduces herself to all nurses and explained the purpose and importance of the study hence, Questionnaire sheet: It was handed to all participant nurses to fill it before teaching program implementation. The time for the completion of the questionnaire sheet was ranged from 10-15 minutes.

- Theoretical contents based on (Tool I part 2) were given to all nurses on the form of lectures for 30 minutes according to their needs.

- The sessions are done in conference room at urology hospital.

- Needed explanations enquiries in addition to booklet in Arabic language. These teaching contents of the booklet were based on the pre assessment result, the process of data collection and implementation of the program consumed 3 months.

- The program was conducted over three sessions in addition to the preliminary one, two times per week to cover all information related to hematuria.

- Sessions were arranged to take place during break time in different shifts or before beginning of shift, the total sample will be divide into subgroups include 5 nurses each session for better performance and understanding. Preliminary session: In this session the researcher met the participants and explained the objectives, contents, and methods of evaluation of program, duration of session 15 minutes. Session one included: Definition of hematuria, signs and risk factors, causes and management of hematuria, duration of session 30 minutes. Session two included: Hematuria color reference scale, collecting urine specimen, obtaining a urine specimen from urinary catheter, duration of session $30 \quad$ minutes. Session three included: Removing an indwelling catheter, performing continuous and intermittent closed catheter irrigation, catheter care, duration of session 30 minutes.

- Group discussion was encouraged with continuous feedback to ensure understanding and achievement of the specific objectives of program.

- An open channel of communication was established between the researcher and nurses to answer any question and reinforce the gained information and correlations.

- Each session started by revision of the previous sessions, taking into consideration the use of simple language. Motivation and reinforcement techniques such as praising and recognition during the program sessions were used to enhance learning.

- In the last session the researcher summarized and emphasized the important points.

- Each nurse demonstrates individually and completely performed the steps during seesions and redemonstrates the steps after one month.

\section{Evaluation of program}

The evaluation of program was carried out immediately after the application of the program using the pre-test study tools one and two in order to test the effectiveness of the program on nurses' knowledge and performance, Data was collected by the researcher during approximately 3 months from July 2018 to September 2018.

\section{Statistical analysis}

Data entry was done and data analyzed, categorized and then coded, were done with the IBM SPSS 20.0 software. The data were tested for normality using the Anderson-Darling test and for homogeneity variances prior to further statistical analysis. Categorical variables were described by number and percent ( $\mathrm{N} \%)$, where continuous variables described by mean and standard deviation (Mean, SD). ChiSquare test and fisher exact test used to compare between categorical variables where compare between continuous variables by T-test and ANOVA Test. A two-tailed $\mathrm{p}<0.05$ was considered statistically significant. We are Used person Correlation to Appear the Association between scores. 


\section{Result}

Table (1): Distribution of demographic data for Studied Nurses $(n=50)$.

\begin{tabular}{|l|c|c|}
\hline Variable & No.(n=50) & \% \\
\hline Age group & 32 & 64.0 \\
\hline $20-25$ year & 13 & 26.0 \\
\hline $25-30$ year & 5 & 10.0 \\
\hline more than 30 year & \multicolumn{2}{|c|}{$20.06 \pm 6.07(21-45)$} \\
\hline Mean \pm SD(range) & \multicolumn{2}{|c|}{} \\
\hline Experience year & 7 & 14.0 \\
\hline Less than 1 year & 19 & 38.0 \\
\hline 1-2 year & 12 & 24.0 \\
\hline 3-5 year & 12 & 24.0 \\
\hline 5-10years & & \\
\hline Gender & 33 & 66.0 \\
\hline Male & 17 & 34.0 \\
\hline Female & & 46.0 \\
\hline Work place & 23 & 54.0 \\
\hline Urology intensive care unit & 27 & 30.0 \\
\hline Emergency department Urology & & 66.0 \\
\hline Education Level & 15 & 4.0 \\
\hline Nursing diploma & 33 & \\
\hline Nursing Technician Institute & 2 & \\
\hline Nursing baccalaureate & \multicolumn{2}{|c|}{} \\
\hline
\end{tabular}

Table (2): Distribution of Mean \pm SD of nurses' knowledge pre and post teaching program regarding hematuria. ( $N=50)$.

\begin{tabular}{|c|c|c|c|c|c|c|}
\hline \multirow{2}{*}{ Variable } & \multirow{2}{*}{$\begin{array}{l}\text { Max } \\
\text { score }\end{array}$} & \multicolumn{2}{|c|}{ Pre } & \multicolumn{2}{|c|}{ Post } & \multirow{2}{*}{ P. value } \\
\hline & & Mean \pm SD & Range & Mean \pm SD & Range & \\
\hline Definition of hematuria & 2 & $1.58 \pm 0.78$ & $0-2$ & $1.96 \pm 0.2$ & $1-2$ & $0.001 * *$ \\
\hline Types of blood in urine & $\overline{1}$ & $0.52 \pm 0.5$ & $0-1$ & $0.92 \pm 0.27$ & $0-1$ & $<0.001 * *$ \\
\hline Signs of hematuria & 1 & $0.52 \pm 0.5$ & $0-1$ & $0.96 \pm 0.2$ & $0-1$ & $<0.001 * *$ \\
\hline Causes of hematuria & 3 & $0.6 \pm 0.7$ & $0-3$ & $2.7 \pm 0.46$ & $2-3$ & $<0.001 * *$ \\
\hline People at high risk for hematuria & 3 & $0.48 \pm 0.79$ & $0-3$ & $2.92 \pm 0.27$ & $2-3$ & $<0.001 * *$ \\
\hline How is hematuria diagnosed & 3 & $0.3 \pm 0.61$ & $0-2$ & $2.44 \pm 0.54$ & $1-3$ & $<0.001 * *$ \\
\hline $\begin{array}{l}\text { Nursing care for patient's with } \\
\text { hematuria }\end{array}$ & 4 & $0.42 \pm 0.88$ & $0-4$ & $2.92 \pm 0.88$ & $1-4$ & $<0.001 * *$ \\
\hline Grading scale for hematuria & 3 & $0.88 \pm 0.98$ & $0-3$ & $2.82 \pm 0.44$ & $1-3$ & $<0.001 * *$ \\
\hline Total Knowledge & 20 & $5.3 \pm 3.88$ & 0-17 & $17.64 \pm 1.78$ & 13-20 & $<0.001 * *$ \\
\hline
\end{tabular}

- Independent T- test $* *$ Significant difference at $p$. value $<0.01$

Table (3): Comparison between Nurses practice during program phases (Pre \&post)

\begin{tabular}{|l|c|c|c|c|}
\hline \multicolumn{1}{|c|}{ Variable } & Score & Pre & Post & P.value \\
\hline Collecting a urine specimen(clean catch, midstream ) & 12 & $2.08 \pm 3.19$ & $11.3 \pm 1.22$ & $<0.001^{* *}$ \\
\hline (Obtaining a urine specimen from urinary catheter): & 20 & $4.14 \pm 5.05$ & $18.56 \pm 1.62$ & $<0.001^{* *}$ \\
\hline (Removing an indwelling catheter): & 20 & $5.38 \pm 4.62$ & $18.38 \pm 2.38$ & $<0.001^{* *}$ \\
\hline (Performing intermittent closed catheter irrigation): & 28 & $5.4 \pm 5.31$ & $25.94 \pm 2.56$ & $<0.001^{* *}$ \\
\hline (Administering continuous closed catheter irrigation): & 20 & $3.24 \pm 3.51$ & $18.78 \pm 1.73$ & $<0.001^{* *}$ \\
\hline Catheter care & 50 & $6.36 \pm 6.76$ & $46.72 \pm 4.41$ & $<0.001^{* *}$ \\
\hline Total chick List & $\mathbf{1 5 0}$ & $\mathbf{2 6 . 6 \pm 2 0 . 3 8}$ & $\mathbf{1 3 9 . 6 8} \pm \mathbf{8 . 9 1}$ & $<\mathbf{0 . 0 0 1}$ * $^{* *}$ \\
\hline
\end{tabular}

- Independent T- test $* *$ Significant difference at p. value $<0.01$ 
Table (4): Correlation Co- efficient between Practice score and Knowledge score

\begin{tabular}{|l|c|c|c|c|}
\hline \multicolumn{1}{|c|}{ Correlation } & Score & Mean \pm SD & $\mathrm{R}$ & $\mathrm{P}$ \\
\hline Total Knowledge score & 20 & $11.47 \pm 6.89$ & \multirow{2}{*}{0.865} & $<0.001 * *$ \\
\hline Total Practice score & 150 & $83.14 \pm 58.94$ & & $<$ \\
\hline
\end{tabular}

-Statistically Significant Correlation at p. value $<0.01$

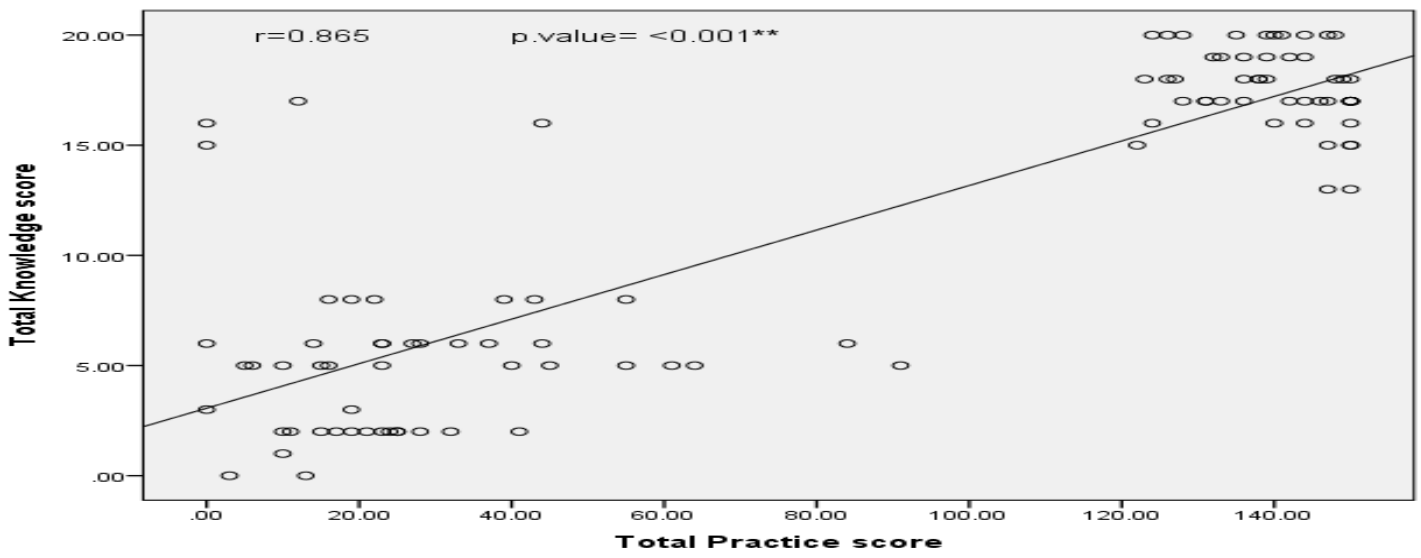

Figure (1): Correlation Co- efficient between total Practice score and Knowledge score.

Table (5): Relationship between Urine color scale degree with Knowledge and Practice for Nurses pre and post education Program.

\begin{tabular}{|c|c|c|c|c|c|c|c|c|}
\hline \multirow{3}{*}{ Urine color scale degree } & \multicolumn{4}{|c|}{ Total Knowledge Score } & \multicolumn{4}{|c|}{ Total Practice score } \\
\hline & \multicolumn{2}{|c|}{ Pre education } & \multicolumn{2}{|c|}{ post education } & \multicolumn{2}{|c|}{ Pre education } & \multicolumn{2}{|c|}{ post education } \\
\hline & Mean \pm SD & Range & Mean \pm SD & Range & Mean \pm SD & Range & Mean \pm SD & Range \\
\hline Poor & $5.27 \pm 4.48$ & $2-16$ & $17.5 \pm 0.71$ & $17-18$ & $15 \pm 10.09$ & $0-28$ & $133 \pm 7.07$ & $128-138$ \\
\hline Fair & $5.25 \pm 4.07$ & $0-17$ & $16.5 \pm 2.12$ & $15-18$ & $23.21 \pm 13.07$ & $0-44$ & $124 \pm 2.83$ & $122-126$ \\
\hline Good & $5.57 \pm 1.13$ & $5-8$ & $17.7 \pm 1.81$ & $13-20$ & $65 \pm 16.6$ & $45-91$ & $140.65 \pm 8.44$ & $123-150$ \\
\hline P. value & \multicolumn{2}{|c|}{0.981} & \multicolumn{2}{|c|}{0.654} & \multicolumn{2}{|c|}{$<0.001 * *$} & \multicolumn{2}{|c|}{$0.016 *$} \\
\hline
\end{tabular}

- Anova test $*$ Significant difference at $p$. value $<0.05$, ** Significant difference at $p$. value $<0.01$

Table (6): Relationship between Nurses' Knowledge score with their demographic data.

\begin{tabular}{|c|c|c|c|c|}
\hline \multirow{3}{*}{ Variable } & \multicolumn{4}{|c|}{ Knowledge score } \\
\hline & \multicolumn{2}{|c|}{ pre education } & \multicolumn{2}{|c|}{ post education } \\
\hline & Mean \pm SD & Range & Mean士SD & Range \\
\hline \multicolumn{5}{|l|}{ Age group } \\
\hline 20-25 year & $5.97 \pm 4.27$ & $1-17$ & $17.94 \pm 1.92$ & $13-20$ \\
\hline 25-30 year & $4 \pm 2.71$ & $0-8$ & $16.85 \pm 1.46$ & $15-20$ \\
\hline more than 30 year & $4.4 \pm 3.29$ & $2-8$ & $17.8 \pm 1.1$ & $16-19$ \\
\hline P.value & \multicolumn{2}{|c|}{0.266} & \multicolumn{2}{|c|}{0.174} \\
\hline \multicolumn{5}{|l|}{ Gender } \\
\hline Male & $5.24 \pm 3.96$ & $0-17$ & $17.91 \pm 1.55$ & $15-20$ \\
\hline Female & $5.41 \pm 3.83$ & $0-16$ & $17.12 \pm 2.12$ & $13-20$ \\
\hline P.value & \multicolumn{2}{|c|}{0.885} & \multicolumn{2}{|c|}{0.138} \\
\hline \multicolumn{5}{|l|}{ Work place } \\
\hline Urology intensive care unit & $6.09 \pm 4.53$ & $0-16$ & $17.65 \pm 1.94$ & $13-20$ \\
\hline $\begin{array}{l}\text { Urology emergency } \\
\text { department }\end{array}$ & $4.63 \pm 3.15$ & $1-17$ & $17.63 \pm 1.67$ & $13-20$ \\
\hline P.value & \multicolumn{2}{|c|}{0.188} & \multicolumn{2}{|c|}{0.965} \\
\hline
\end{tabular}




\begin{tabular}{|c|c|c|c|c|}
\hline \multirow{3}{*}{ Variable } & \multicolumn{4}{|c|}{ Knowledge score } \\
\hline & \multicolumn{2}{|c|}{ pre education } & \multicolumn{2}{|c|}{ post education } \\
\hline & Mean \pm SD & Range & Mean+SD & Range \\
\hline \multicolumn{5}{|l|}{ Experience year } \\
\hline Less than 1 year & $7.14 \pm 6.26$ & $2-17$ & $19.57 \pm 1.13$ & $17-20$ \\
\hline $1-2$ year & $5.53 \pm 3.19$ & $1-16$ & $17.58 \pm 1.57$ & $13-20$ \\
\hline 3-5 year & $4.5 \pm 4.36$ & $0-16$ & $16.83 \pm 1.99$ & $13-20$ \\
\hline 5-10years & $4.67 \pm 2.57$ & $2-8$ & $17.42 \pm 1.51$ & $15-20$ \\
\hline P.value & \multicolumn{2}{|c|}{0.491} & \multicolumn{2}{|c|}{$0.009 * *$} \\
\hline \multicolumn{5}{|l|}{ Education Level } \\
\hline Nursing diploma & $5.47 \pm 3.5$ & $2-15$ & $17.33 \pm 1.91$ & $13-20$ \\
\hline $\begin{array}{l}\text { Nursing Technician } \\
\text { Institute }\end{array}$ & $5.33 \pm 4.16$ & $0-17$ & $17.79 \pm 1.78$ & $13-20$ \\
\hline Nursing baccalaureate & $3.5 \pm 2.12$ & $2-5$ & $17.5 \pm 0.71$ & $17-18$ \\
\hline P.value & \multicolumn{2}{|c|}{0.801} & \multicolumn{2}{|c|}{0.719} \\
\hline
\end{tabular}

- Independent T- test

- Anova test ** Significant difference at p. value $<0.01$

Table (7): Relationship between Nurses' Practice score with their demographic data.

\begin{tabular}{|c|c|c|c|c|}
\hline \multirow{3}{*}{ Variable } & \multicolumn{4}{|c|}{ Practice score } \\
\hline & \multicolumn{2}{|c|}{ Pre education } & \multicolumn{2}{|c|}{ post education } \\
\hline & Mean \pm SD & Range & Mean \pm SD & Range \\
\hline \multicolumn{5}{|l|}{ Age group } \\
\hline 20-25 year & $28.47 \pm 23.45$ & $0-91$ & $139.75 \pm 8.56$ & $123-150$ \\
\hline $25-30$ year & $23.08 \pm 14.53$ & $0-45$ & $141.46 \pm 9.32$ & $122-150$ \\
\hline more than 30 year & $23.8 \pm 10.76$ & $10-39$ & $134.6 \pm 10.09$ & 124-149 \\
\hline P. value & \multicolumn{2}{|c|}{0.695} & \multicolumn{2}{|c|}{0.349} \\
\hline \multicolumn{5}{|l|}{ Experience year } \\
\hline Less than 1 year & $37.43 \pm 36.38$ & $0-91$ & $139.14 \pm 9.67$ & $124-150$ \\
\hline $1-2$ year & $23.32 \pm 16.65$ & $0-61$ & $140.32 \pm 8.63$ & $123-150$ \\
\hline 3-5 year & $23.17 \pm 20.91$ & $0-64$ & $143 \pm 7.62$ & $128-150$ \\
\hline 5-10years & $28.92 \pm 11.2$ & $10-45$ & $135.67 \pm 9.6$ & $122-150$ \\
\hline P. value & \multicolumn{2}{|c|}{0.407} & \multicolumn{2}{|c|}{0.242} \\
\hline \multicolumn{5}{|l|}{ Gender } \\
\hline Male & $25.15 \pm 22.15$ & $0-91$ & $138.58 \pm 9.67$ & $122-150$ \\
\hline Female & $29.41 \pm 16.69$ & $10-64$ & $141.82 \pm 6.98$ & $126-150$ \\
\hline P.value & \multicolumn{2}{|c|}{0.489} & \multicolumn{2}{|c|}{0.226} \\
\hline \multicolumn{5}{|l|}{ Work place } \\
\hline $\begin{array}{l}\text { Urology intensive care } \\
\text { unit }\end{array}$ & $22.87 \pm 20.07$ & $0-84$ & $140.3 \pm 8.84$ & $122-150$ \\
\hline $\begin{array}{l}\text { Urology Emergency } \\
\text { department }\end{array}$ & $29.78 \pm 20.48$ & $0-91$ & $139.15 \pm 9.1$ & $123-150$ \\
\hline P. value & \multicolumn{2}{|c|}{0.236} & \multicolumn{2}{|c|}{0.652} \\
\hline \multicolumn{5}{|l|}{ Education Level } \\
\hline Nursing diploma & $27.33 \pm 12.92$ & $0-45$ & $137.4 \pm 9.4$ & $122-150$ \\
\hline $\begin{array}{l}\text { Nursing Technician } \\
\text { Institute }\end{array}$ & $26.85 \pm 23.54$ & $0-91$ & $140.39 \pm 8.81$ & $123-150$ \\
\hline Nursing baccalaureate & $17 \pm 9.9$ & $10-24$ & $145 \pm 4.24$ & $142-148$ \\
\hline P. value & \multicolumn{2}{|c|}{0.393} & \multicolumn{2}{|c|}{0.798} \\
\hline
\end{tabular}

Independent T- test

- Anova test ** Significant difference at p. value $<0.01$. 
Table (1): Shows that regarding demographic data of studied nurses, it was found that $64.0 \%$ of studied nurses were in the age group from 20 to 25 years with mean age $20.06 \pm 6.07$ (21-45), $66.0 \%$ were male. Concerning their educational Level, $66.0 \%$ of the nurses held nursing technician institute. Moreover, $38.0 \%$ of nurses had years of experience from 1 to 2 years.

Table (2): Showed that there was a significant difference between pre teaching program and posttest regarding all items of hematuria, in addition there were a significant improvement in the total knowledge scores post application of teaching program

Table (3): Illustrate that comparison between pre and post teaching program about total nurses practice scores, there were a highly significant difference, in addition to there was an improvement after the application of the teaching program.

Table (4) \& Figure(1): Showed that there was appositive correlation between studied nurses' total practice and total knowledge scores.

$(\mathrm{r}=.865$ and $\mathrm{P}$. value $=<0.001)$

Table (5): Showed that there was a statistical signification difference between urine color scale degree and total nurses' practice score before and after education Program. In addition, there was no statistical signification difference between urine color scale degree and total nurses' knowledge score before and after education program

Table (6): showed that there was no significant statistical difference between total nurses knowledge scores either pre and post test and their demographic data except years of experience there was a significant statistical difference and post test knowledge scores.

Table (7): showed that there was no significant statistical difference between total nurses practice scores either pre and post test and their demographic data

\section{Discussion}

The present study aimed to evaluate the effect of teaching program about hematuria on nurses' performance at urology intensive care unit. This discussion will cover the main result findings as follow:

The present study showed that more than half of studied nurses were male this not incompatible with Redwood et al., (2018) who found most of nurses working in urology department were females. Concerning their educational Level, majority of the nurses held nursing technician institute. Moreover, around quarter of nurses had years of experience from 1 to 2 years. This finding in the same line with, (Naqib et al., 2018). Regarding socio-demographic data of studied nurses in renal department, it was found that majority of them were in the age group from 20 to 25 years with mean age 20.06 $\pm 6.07(21$ 45), this agreed with Weber et al., (2011) who found that the mean age was between 22-24 years old.

From the result of the present study, it showed that there was a significant difference between pre and post teaching program regarding all items of hematuria; in addition there were a significant improvement in the total knowledge scores post application of teaching program

The current study revealed a great improvement in knowledge score about hematuria after application of the teaching program. In the same line, Kaushal, (2015) emphasize the positive impact of a training program on the knowledge scores hence the healthcare organizations can engage in continuous training programs to regularly maintain and enhance the knowledge of the nurses.

Cooper, (2019) found that; technique. A pre- and post-test were administered; the mean pretest score was $72.1 \%$ and the mean posttest score was $94.1 \%$. Comparison of pre- and post-test scores reflect a $22 \%$ increase in test scores, therefore, this program increased knowledge. This project can contribute to positive social change by improving nursing practice through increasing nurses' knowledge of proper care of hematuria, which can translate into evidence-based practice changes and improve patient outcomes.

Regarding baseline nurses practice about (administering continuous closed catheter irrigation), showed that majority of studied nurses did not assess the patient's response to the procedure, note characteristics and amount of urine in drainage bag after irrigation. In addition, most of them did not perform neither confirm the order for catheter irrigation in the medical record nor gather equipment, Samineni et al., (2017). Emphasized in their study that pain is the main complain of the urinary bladder irrigation, so the nurse should monitor patients response specially pain in addition to the color of urine drainage which indicated presence of hematuria or absence.

Regarding baseline nurses practice about catheter care, showed that all studied nurses did not introduce self and verify patient's identity, explain procedure to the patient or assess flow of urine through tubing and not report any unusual findings immediately.

Nurse plays an essential role in caring of patients with hematuria especially in catheter care. In this concern, the nurse could gain the patient cooperation by explaining the procedure and its purpose to him/her. In addition reporting all findings to the physician immediately consider the main step for early detection and management for any unexpected out comes, Richards et al., (2017). 
The relation of age and years of experience observed during the pretest may be attributed to the transfer of inappropriate knowledge and practice from old to new nurses, who in turn lead to following the same mistakes in caring for patients. These results agree with the study of Abd -El Mohsen \& Khalil (2016) revealed that no significant difference between nurse's practice scores with their years of experience observed during pre-test.

The exciting study showed that there was no significant statistical difference between total nurses knowledge scores either pre and post test and their demographic data except years of experience there was a significant statistical difference and post test knowledge scores .In addition there was no significant statistical difference between total nurses practice scores either pre and post test and their demographic data

The score of knowledge high in nurses there age 2025 years of age; this age group might have good readiness for learning new things, also the score of knowledge was high in nurses whom years of experience ranged from 5 to 10 years and in male rather than female. These results are in agreement with those of Shehab et al., (2018), who noted that nurses' knowledge scores were higher among younger and newly graduated nurses who attend training program

From the result of the contemporaneous study showed that there was a significant statistical difference (p. value<0.001) between before and after the teaching program regarding urine color scale. In addition majority of them were good degree in urine color scale after teaching program application. As well, showed that there was a statistical signification difference between urine color scale degree and total nurses' practice score before and after education program.

Finally, the findings of the present study supported the research hypothesis that nurses in urology ICU who received the teaching program about hematuria care showed a high score of knowledge and practice after test than that before.

\section{Conclusions}

Based on the result of the present study, it can be concluded that:

-Nurse`s knowledge and practice regarding patients with hematuria in urological intensive care unit at Assiut university hospital are poor, implementing the teaching program on nurse's knowledge and nurse's practice shows a significant improvement which affect their performance.

\section{Recommendations}

Based on results of the present study the following can be recommended:

1. Continuous nursing education and in service training programs on urological intensive care unit should be well organized at Assiut university hospital.

2. Nurses should add to their routine obligations the regular reading of up-to-date references (periodical, textbooks, etc.) and encouraged to attend scientific meetings and conferences to keep pace with the rapidly growing wealth of knowledge and practice necessary for proper nursing service.

3. Orientation program for all newly nurses about hematuria, and its complications, Presence and reviewing of patient's records for proper follow up for patients with hematuria.

\section{References}

1. Abd - El mohsen S., \& Khalil S., (2017): Relationship between health-related quality of life and self-esteem of adult patients receiving chemotherapy for cancer treatment, International Journal of Advanced Nursing Studies, 6 ( 1 ), P.P. 63 -66

2. Bayoumi M., Mahmoud N., (2017): Effect of education program on nurses' knowledge and practice regarding care of central venous line in pediatric hemodialysis: evidence-based practice guidelines, Egyptian Nursing Journal, Vol. 14 No. 2, P.P. :87-99

3. Cooper, M., (2019): Improving Nurses' Knowledge of Central Line-Associated Blood stream Infection., Walden Dissertations and Doctoral Studies, Walden University scholarworks), P.P:40-47

4. Derek Hicks, Chi-Ying Li, (2007): Management of macroscopic hematuria in the emergency department, Emergency Medical Journal 24:385-390.

5. Groninger H., \& Jayne M., Phillips, (2012), Gross Hematuria: Assessment and Management at the End ofLife, National Institutes of Health Clinical Center, Bethesda, MD , 2012 May 12; 14(3): 184-188.

6. Grossfeld G., Wolf J., Litwin M., Hricak H., Shuler C., Agerter D., Carroll P., (2001): Asymptomatic Microscopic Hematuria in Adults: Summary of the AUA Best Practice , Policy Recommendations, American Family Physician, 63 (6) accessed May 7, 2011:

7. India PvT, (2014): fundamentals of nursing, $1400-1405,1^{\text {st }}$ edition.

8. Kaushal G., (2015): Impact of Training on Knowledge, Attitude and Practices Scores of 
ICU Nurses regarding Standard Precautions of Infection Control in a Super Speciality Hospital of Delhi, Indian Journal of Research, 4, (8), 282-285

9. Koo, K., Lee, K., Choi, A., Rha, K., Hong, S., \& Chung, B., (2016): Diagnostic impact of dysmorphic red blood cells on evaluating microscopic hematuria: the urologist's perspective. International urology and nephrology, 48(7), 1021-1027

10. Meagher A., Thompson J., \& Vanderpuije J., (2014): Developing and testing a urine color reference scale: a practice development project. International journal of urological nursing. Vol 8 No 3: $122-129$.

11. Moreno, J., Yuste, C., Gutiérrez, E., Sevillano, Á., Rubio-Navarro, A., AmaroVillalobos, J., \&Egido, J., (2016): Haematuria as a risk factor for chronic kidney disease progression in glomerular diseases: A review. Pediatric nephrology, 31(4), 523-533.

12. Naqib, D., Purvin, M., Prasad, R., Hanna, I., Dimitri, S., Llufrio, A., \& Hanna, M., (2018): Quality Improvement Initiative to Improve Postoperative Pain with a Clinical Pathway and Nursing Education Program. Pain Management Nursing, 19(5), 447-455.

13. Pamela Lynn, (2015): Skill checklist for Taylor's clinical nursing skills, by Wolters Kluwer , Nursing Skills: A nursing Process Approach,4th edition.

14. Redwood, R., Knobloch, M., Pellegrini, D., Ziegler, M., Pulia, M., \&Safdar, N., (2018): Reducing unnecessary culturing: a systems approach to evaluating urine culture ordering and collection practices among nurses in two acute care settings. Antimicrobial Resistance \& Infection Control, 7(1), 4.

15. Richards, B., Sebastian, B., Sullivan, H., Reyes, R., D'Agostino, J., \&Hagerty, T., (2017): Decreasing catheter-associated urinary tract infections in the neurological intensive care unit: One unit's success. Critical care nurse, 37(3), 42-48

16. Samineni, V., Mickle, A., Yoon, J., GrajalesReyes, J., Pullen, M., Crawford, K., \& Rogers, J., (2017): Optogenetic silencing of nociceptive primary afferents reduces evoked and ongoing bladder pain. Scientific reports, 7(1), 15865

17. Shehab, M., Ibrahim, N., \& Abd-Elkader, H., (2018): Impact of an Educational Program on Nurses' Knowledge and Practice Regarding Care of Traumatic Brain Injury Patients at Intensive Care Unit at Suez Canal University
Hospital. International Journal of Caring Sciences, 11(2), 1104.

18. Urden, L., Stacy, K., Lough, M., (2016): Priorities in Critical Care Nursing, Elsevier Inc, 793-797.

19. Weber J., Sickbert-Bennett E., Gould V., Brown M., Huslage K., Rutala A., (2011): :Incidence of catheter-associated and noncatheter-associated urinary tract infections in a healthcare system. Infect Control HospEpidemiol.; 32(8):822-823

20. Yuste, C., Gutierrez, E., Sevillano, A., RubioNavarro, A., Amaro-Villalobos, J., Ortiz, A., \& Moreno, J., (2015): Pathogenesis of glomerular haematuria. World journal of nephrology, 4(2), 185 